\title{
Alterações eletromiográficas e histopatológicas da musculatura de cães naturalmente infectados por Leishmania infantum
}

\author{
Muscular electromyographic and histopathologic changes in dogs naturally infected by \\ Leishmania infantum
}

\author{
Gisela Cristiane FERRARO ${ }^{1}$; Gisele Fabrino MACHADO ${ }^{2}$; Márcia Dalastra LAURENTI ${ }^{3}$; Mauro \\ Henrique BUENO DE CAMARGO ${ }^{1}$; Ana Amélia Domingues GOMES ${ }^{1,4}$; Denis Carvalho COSTA ${ }^{2}$; \\ Camila Mariana VIEIRA²; Celina Bertelli SIMÕES ${ }^{2}$; Valéria Marçal Félix de LIMA²; Mary \\ MARCONDES $^{2}$
}

${ }^{1}$ Faculdade de Ciências Agrárias e Veterinárias da Universidade Estadual Paulista, Jaboticabal - SP, Brasil

${ }^{2}$ Faculdade de Medicina Veterinária da Universidade Estadual Paulista, Araçatuba - SP, Brasil. ${ }^{3}$ Faculdade de Medicina da Universidade de São Paulo, São Paulo - SP, Brasil

${ }^{4}$ Faculdade de Medicina Veterinária da Universidade Federal do Vale do São Francisco, Petrolina - PE, Brasil

\begin{abstract}
Resumo
O objetivo do presente estudo foi avaliar as alterações eletromiográficas e histopatológicas de músculos estriados esqueléticos de cães naturalmente infectados por Leishmania infantum. Foram selecionados 25 cães adultos, sem raça definida, com diagnósticos parasitológico, molecular e sorológico estabelecidos para a infecção. Os músculos avaliados foram: tríceps braquial, extensor carpo radial, bíceps femoral e gastrocnêmio. Um cão possuía problemas locomotores, com paresia de membros posteriores associada à intensa atrofia muscular. Vinte e três (92\%) apresentavam algum tipo de alteração muscular, sendo que em 22 (88\%) tais alterações foram identificadas diretamente pela eletromiografia. Mesmo sem sinais clínicos, em dez cães (40\%) foram evidenciadas alterações eletromiográficas e histopatológicas. Antígenos de Leishmania foram identificados na musculatura de quatro (16\%) cães. Os resultados eletromiográficos indicaram a ocorrência de polimiosite crônica em 13 (52\%) cães, presença de músculos com inflamação tanto aguda quanto crônica em quatro (16\%), miopatia aguda em dois (8\%), e ausência de alterações eletromiográficas em três (12\%). As alterações histopatológicas mais frequentemente observadas foram degeneração e necrose de miofibras e presença de infiltrado inflamatório verificadas em 12 (48\%) cães. Outras alterações, quando comparado com as amostras de cães normais, foram do tamanho de grupos de fibras musculares em 15 (60\%) e fibrose peri ou endomisial em 14 (56\%) animais. As alterações observadas no presente estudo permitiram concluir que mesmo na ausência de sinais clínicos de comprometimento muscular, a maior parte dos cães infectados por L. infantum apresenta polimiosite crônica.
\end{abstract}

Palavras-chave: Leishmania infantum. Leishmaniose visceral canina. Miopatia. Polimiosite.

\begin{abstract}
The aim of this study was to evaluate the electromyographic and histopathological changes in skeletal muscles of dogs naturally infected by L. infantum. Twenty five mixed breed adult dogs with parasitological, molecular and serological diagnosis were selected. The evaluated muscles were: triceps brachial, extensor carpi radialis, biceps femoris and gastrocnemius. One dog had locomotor clinical signs with hind limbs paresis associated with severe muscle atrophy. Twenty-three (92\%) had some type of muscular change, and in $22(88 \%)$ such changes were directly identified by electromyography. Even without any clinical signs of the disease, $10(40 \%)$ dogs had electromyographic and histopathological changes. Leishmania antigens were detected in muscles of four (16\%) dogs. The electromyographic evaluation indicated the occurrence of chronic polymyositis in $13(52 \%)$ dogs, the presence of both acute and chronic muscle inflammation four (16\%), acute myopathy in two (8\%) and absence of electromyographic abnormalities in three (12\%) dogs. The most frequently observed histopathological changes were degeneration and necrosis of myofibers and inflammatory infiltration observed in 12 (48\%) dogs. Other changes were decreased diameter of muscle fibers in $15(60 \%)$ and peri or endomysial fibrosis in $14(56 \%)$ animals. The changes observed in the present study showed that even in the absence of clinical signs, most dogs infected by Leishmania infantum have chronic polymyositis.
\end{abstract}

Keywords: Leishmania infantum. Canine visceral leishmaniasis. Myopathy. Polymyositis.

Correspondência para:

Mary Marcondes

Departamento de Clínica, Cirurgia e Reprodução Animal

Faculdade de Medicina Veterinária

Universidade Estadual Paulista Júlio de Mesquita Filho

Rua Clóvis Pestana, 793, Jardim Dona Amélia
Araçatuba, SP - Brasil

CEP: $16050-680$

Tel.: +55 18 3636-1415; Fax: +55 18 3622-4542

E-mail: marcondes@fmva.unesp.br

Recebido: 21/06/2011

Aprovado: $31 / 10 / 2012$ 


\section{Introdução}

A leishmaniose visceral canina (LVC) é uma doença causada no Brasil pela Leishmania infantum e que pode atingir praticamente todos os sistemas do organismo. Problemas no sistema locomotor levam à claudicação, impotência funcional ou paresia de membros em decorrência de quadros de poliartrite, polimiosite e até osteomielite. Eventualmente, ulcerações interdigitais e edema de membros também podem causar dificuldade locomotora ${ }^{1,2,3,4,5,6,7}$.

Muitos cães apresentam mioatrofia, inicialmente nos músculos das fossas temporais, seguida, sucessivamente, pelo resto da musculatura do corpo. A atrofia muscular progressiva pode ser mais proeminente nos músculos mastigatórios, e é atribuída à natureza catabólica da doença ${ }^{3,8}$.

Embora existam alguns relatos de casos de miosite em decorrência de leishmaniose visceral (LV) ${ }^{8,9,10}$, pouco se sabe sobre a etiopatogenia das alterações musculares em cães. Estudos histopatológicos têm sido realizados na musculatura lisa e esquelética de cães com LV, incluindo músculos mastigatórios ${ }^{8}$, apendiculares $^{8,11}$, intra, peri e extraoculares ${ }^{12}$, cardí$\operatorname{acos}^{13,14,15}$, bronco-pulmonares ${ }^{13}$ e intestinais ${ }^{16}$. Tais avaliações revelaram a presença de infiltrado inflamatório composto por macrófagos, linfócitos e neutrófilos, áreas de degeneração, atrofia e necrose de miofibras, vasculite neutrofílica, proliferação de tecido conectivo fibroso e, em alguns casos, presença de formas amastigotas de Leishmania sp., ${ }^{8,9}$. Isto leva a crer que as alterações musculares observadas em cães com a doença não sejam apenas decorrentes de catabolismo e perda progressiva de peso, mas sim de processo inflamatório que poderia ser desencadeado pela presença do parasito na musculatura.

Para caracterizar as lesões musculares de cães com LV, o presente estudo teve como objetivos determinar as alterações eletromiográficas e histopatológicas, bem como a presença de formas amastigotas, na mus- culatura estriada esquelética de cães naturalmente infectados por L. infantum.

\section{Material e Método}

Vinte e cinco cães adultos, sem raça definida, naturalmente acometidos por LV, encaminhados ao Hospital Veterinário da Faculdade de Medicina Veterinária - UNESP, Araçatuba, São Paulo, área enzoótica da infecção em cães, foram selecionados para o presente estudo. O diagnóstico baseou-se em sorologia por ELISA para pesquisa de anticorpos anti-Leishmania infantum, segundo Lima et al. ${ }^{17}$, confirmado pela identificação de formas amastigotas do parasita em esfregaços obtidos por punções biópsias aspirativas de linfonodos e de medula óssea, e pela Reação em Cadeia da Polimerase (PCR) de medula óssea. Quatro cães não infectados, provenientes da mesma área endêmica, foram utilizados como grupo controle. A exclusão da infecção nesses animais baseou-se em sorologia por ELISA, exame parasitológico direto de linfonodos e medula óssea e PCR de linfonodos, medula óssea e de sangue negativos. O DNA para realização da PCR foi extraído do sangue total e das amostras de punção biópsia aspirativa de linfonodos e medula óssea (Dneasy Blood \& Tissue Kit, Qiagen, USA). A reação de PCR foi realizada segundo Nunes et al. ${ }^{18}$. Todos os animais foram submetidos a exame físico completo, seguido da avaliação eletromiográfica. Após a realização da eletromiografia, os animais infectados foram anestesiados com pentobarbital sódico (15 mg/kg/iv) e, em seguida, submetidos a eutanásia com a aplicação intravenosa de uma ampola de $10 \mathrm{~mL}$ de cloreto de potássio a 19,1\%. Após a eutanásia, foram colhidos fragmentos musculares para posterior processamento histopatológico. Nos cães do grupo controle, a biopsia muscular foi realizada em plano anestésico. As avaliações foram realizadas em cortes transversais de músculos estriados esqueléticos proximais e distais dos membros torácico e pélvico. $\mathrm{O}$ 
presente estudo foi aprovado pelo Comitê de Ética e Experimentação Animal da Faculdade de Odontologia e Medicina Veterinária da Universidade Estadual Paulista, UNESP.

Realizou-se a eletromiografia da cabeça longa do músculo tríceps braquial, do músculo extensor carpo radial, do músculo bíceps femoral e da cabeça lateral do músculo gastrocnêmio. Para tanto, utilizou-se aparelho modelo Viking Quest, de dois canais, portátil (Nicolet Compass Meridian - Nicolet Biomedical Inc., EUA). A avaliação muscular foi realizada com agulha monopolar 25 x 0,36 mm (Neuroline - Malásiae Alfamedic $^{\odot}$, Brasil) como eletrodo exploratório, e os pontos de introdução foram os mesmos mapeados por Thomson e Bowen (1971) ${ }^{19}$. Eletrodos superficiais, do tipo jacaré, foram utilizados como eletrodos referência e terra. Avaliou-se a atividade elétrica insersional, atividade elétrica de repouso e atividades elétricas voluntárias mínima e máxima, com base de tempo de $100 \mathrm{~ms} /$ div, sensibilidade de $10 \mu \mathrm{v} /$ div e filtros com banda passante de 10 a $20 \mathrm{KHz}$. Para a avaliação das atividades insersional e de repouso, o animal era mantido em decúbito e imobilizado mecanicamente. Para a atividade elétrica voluntária, estimulava-se inicialmente a flexão do membro com o animal ainda em decúbito e, em seguida, o animal era mantido em estação e aplicava-se força sobre o seu dorso para o mesmo sustentar o corpo e, dessa forma, contrair a musculatura extensora. A frequência das alterações eletromiográficas foi expressa em percentagens em relação ao número de músculos avaliados.

As amostras musculares foram retiradas do membro contralateral ao da realização da eletromiografia. Os fragmentos musculares foram cuidadosamente estirados entre tiras de cortiça e fixados em formol tamponado a $10 \%(\mathrm{pH} 7,4)$ por $24 \mathrm{~h}$, e incluídos em parafina. De cada fragmento foram obtidos cortes transversais e longitudinais de três a cinco micrômetros de espessura, que foram corados com hematoxili- na-eosina (HE) e Tricrômico de Gomori Modificado (TGM).

Para a caracterização histopatológica qualitativa das lesões musculares, foram estabelecidos cinco parâmetros morfológicos, quais sejam, variação no tamanho das fibras musculares, presença de inflamação, proliferação de tecido adiposo no endomísio, degeneração e necrose de miofibras, e presença de fibrose muscular. As alterações foram classificadas semiquantitativamente, de acordo com sua intensidade e distribuição na área avaliada, em uma escala de 0 a 3, onde 0 indicava ausência de lesão, 1 lesão leve (focal), 2 moderada (multifocal) e 3 intensa (difusa), utilizando-se como comparação os animais do grupo controle. Para cada alteração encontrada, somaram-se os escores dos quatro músculos de cada animal, resultando em valores variando de zero (ausência da referida lesão em todos os músculos) a 12 (presença de três cruzes em todos os músculos). O resultado dessa soma foi utilizado para a realização da análise estatística. A frequência das alterações histopatológicas foi expressa em número absoluto e percentagem de músculos avaliados. A comparação entre os grupos foi realizada através da prova não paramétrica de Mann-Whiteny, em nível de significância de 5\%.

Após reidratação dos cortes histológicos, a recuperação antigênica foi realizada em solução de citrato 10 $\mathrm{mM}, \mathrm{pH}$ 6,0 por 30 minutos, seguida pelo bloqueio da peroxidase endógena com peróxido de hidrogênio 10 volumes. O bloqueio de ligações inespecíficas foi realizado com leite em pó desnatado (Molico, Nestlé, São Paulo, Brasil) diluído a $6 \%$ em solução tampão fosfato (PBS) $0,05 \%$ durante uma hora em estufa a $37^{\circ} \mathrm{C}$. Em seguida, o material foi incubado a $4^{\circ} \mathrm{C}$, durante a noite, com anticorpo primário policlonal anti-Leishmania amazonensis, produzido em camundongo, diluído 1:1000 em solução de albumina bovina (BSA) a 1\% em PBS pH 6,0. Os cortes foram lavados com PBS-Tween 20 a $0,05 \%$ e, novamente, incubados em estufa $\left(37^{\circ} \mathrm{C}\right)$ com anticorpo secundário biotinilado e solução de 
Streptoavidina-Peroxidase, conforme recomendação do fabricante (Kit LSAB - K0690 - DakoCytomation CA, USA). A reação final foi revelada com o substrato cromógeno 3,3'-diaminobenzidina (Liquid DAB + Substrate Chromogen System - K3468 - DakoCytomation CA, USA) e a contra-coloração do tecido foi realizada com Hematoxilina de Harris.

\section{Resultados e Discussão}

Dos 25 cães, 10 (40\%) eram assintomáticos e 15 (60\%) apresentavam sinais clínicos como hipertermia, anemia, emagrecimento, lesões cutâneas caracterizadas por dermatite esfoliativa, presença de úlceras, principalmente na face e nos membros, onicogrifose, epistaxe e uveíte. Um cão (4\%) possuía problemas locomotores, com paresia de membros pélvicos associada à intensa atrofia muscular, e sua avaliação neurológica não demonstrou sinais compatíveis com neuropatia periférica. Vinte e três (92\%) cães apresentavam algum tipo de alteração muscular, sendo que em 22 (88\%) tais alterações foram identificadas diretamente pela eletromiografia. Mesmo sem apresentar sinais clínicos da doença, em dez cães (40\%) foram evidenciadas alterações eletromiográficas e histopatológicas. Um animal (4\%) apresentou a eletromiografia e o exame histopatológico dos músculos dentro dos padrões de normalidade.

A fase do exame mais comprometida foi a atividade insersional, seguida pela atividade voluntária e de repouso. Dos 100 músculos avaliados, 44\% possuíam atividade insersional diminuída, indicando a existência de miopatia primária ou secundária à denervação em 17 (68\%) cães. Por outro lado, 9\% dos músculos possuíam atividade insersional aumentada, sugestiva de distúrbio eletrolítico, metabólico, processo inflamatório ou degenerativo acometendo seis (24\%) animais. Em treze (52\%) cães foram observados potenciais espontâneos, caracterizados pela presença de ondas positivas, potenciais de fibrilações e descargas complexas repetitivas durante a atividade de repouso, totalizando $21 \%$ dos músculos avaliados. Quanto à atividade voluntária, $18(72 \%)$ cães $(50 \%$ dos músculos), tiveram recrutamento de fibras alterado, evidenciado por aumento da velocidade de recrutamento das unidades motoras e presença de potenciais polifásicos, pequenos e de curta duração. A avaliação eletromiográfica dos animais do grupo controle encontrava-se dentro dos parâmetros de normalidade. De modo geral, a presença de alterações eletromiográficas foi maior nos membros torácicos do que nos pélvicos, com distribuição similar entre os músculos proximais e distais em cada membro. Os resultados eletromiográficos sugerem que 13 (52\%) animais possuíam polimiopatia crônica, quatro $(16 \%)$ possuíam tanto músculos com inflamação aguda quanto crônica, dois (8\%) possuíam miopatia aguda, enquanto três (12\%) apresentavam eletromiografia normal. Em três (12\%) animais, as alterações eletromiográficas ocorreram em um único músculo, sugerindo um processo inflamatório, entretanto, não permitindo que se estabelecesse diagnóstico de miopatia difusa.

A reação imunohistoquímica revelou a presença de antígenos do parasita (Figura 1A) nos músculos de quatro $(26,7 \%)$ dos 15 cães com sinais clínicos de LV, correspondendo a $16 \%$ do total de cães com a doença. Nos animais do grupo controle não foram identificados antígenos de Leishmania sp. na musculatura.

As alterações histopatológicas mais frequentemente observadas foram degeneração e necrose de miofibras (Figura 1B), verificadas em 12 (48\%) cães e em 59\% dos músculos avaliados. Em algumas áreas de necrose, caracterizadas pela presença de miofibras fragmentadas com aspecto vítreo, observou-se também a ocorrência de regeneração das fibras (Figura 1C), que apresentavam tamanho menor e basofilia, além de núcleo vesicular. Em 24\% dos músculos e em 12 (48\%) animais observou-se infiltrado inflamatório. $\mathrm{Na}$ maioria dos músculos o infiltrado inflamatório era mononuclear (Figura 1D), composto predomi- 


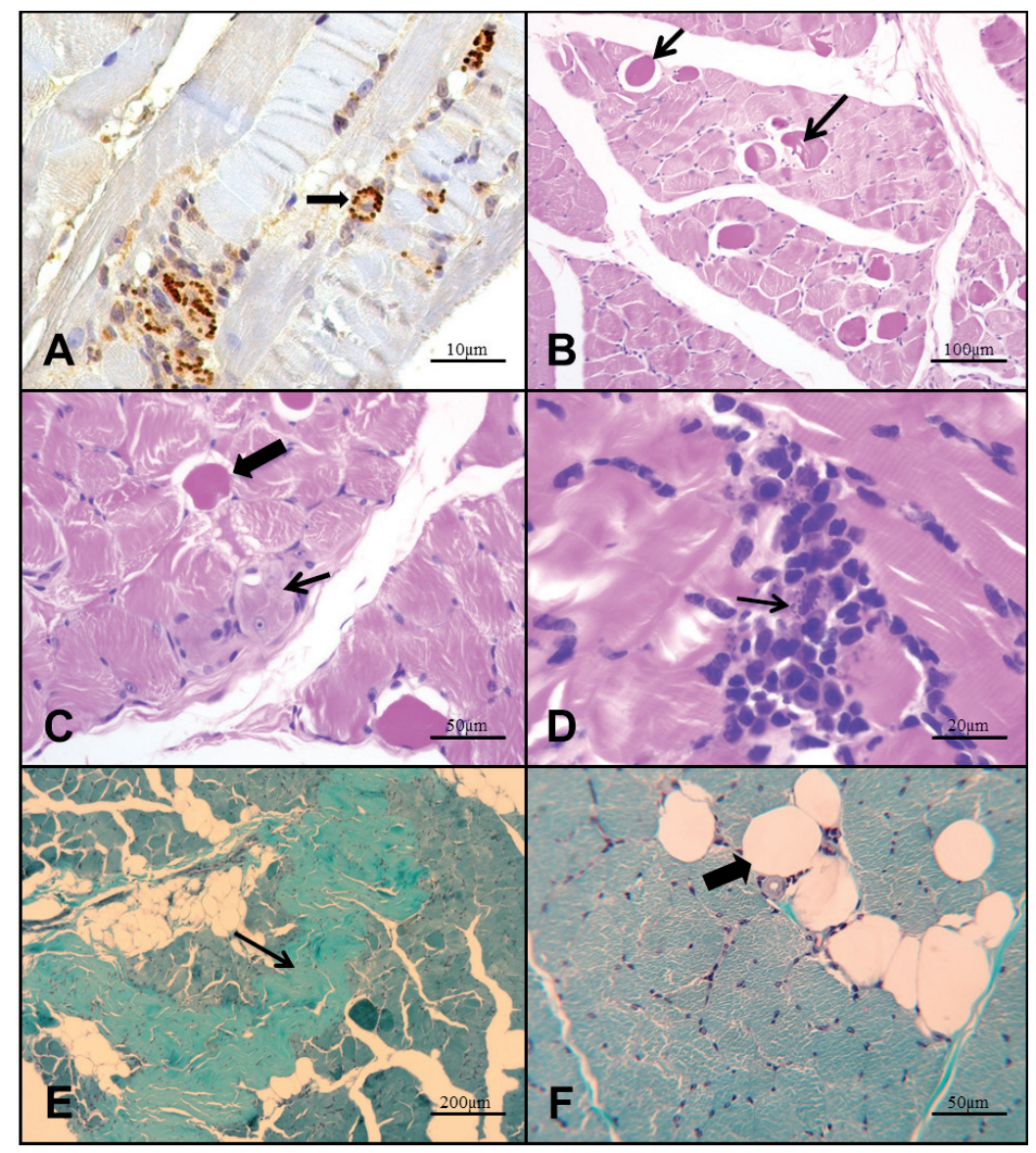

Figura 1 - Fotomicrografia de músculos estriados esqueléticos de cães infectados por L. infantum Legenda: Visualização de formas amastigotas do parasita (seta) através do método de imunohistoquímica - LSAB (A); Necrose de miofibras: observar perda de angulação, eosinofilia e fragmentação do citoplasma (setas) - (HE) (B); Fibras musculares eosinofílicas em necrose (seta larga) e fibras basofílicas em regeneração, com núcleo e nucléolo evidentes (seta estreita) - (HE) (C); Miosite crônica: área com presença de infiltrado inflamatório mononuclear; observar macrófagos com formas amastigotas de Leishmania sp. intracitoplasmáticas (seta) - (HE) (D); Área de substituição de tecido muscular por tecido fibroso (seta) - (TGM) (E); Presença de tecido adiposo no endomísio $\left.{ }^{*}\right)-($ TGM) $(\mathbf{F})$

nantemente por linfócitos e plasmócitos, além de macrófagos evidenciados principalmente no endomísio e, em menor frequência, no perimísio. Em alguns animais evidenciou-se a presença de formas amastigotas do parasita no citoplasma de macrófagos (Figura 1D). A ocorrência de fibrose (Figura 1E) peri ou endomisial foi verificada em 14 (56\%) cães e em $26 \%$ dos músculos avaliados. Em 15 (60\%) cães observou-se, nos cortes transversais, variação no tamanho das miofibras, com presença de redução do tamanho de grupos de fibras musculares, caracterizando atrofia, com distribuição perifascicular. A variação no tamanho das miofibras foi visualizada predominantemente em grupamentos, com distribuição focal, em $22 \%$ dos músculos. Em 15\% das amostras musculares verificou-se atrofia com distribuição multifocal de miofibras (moderada). O tecido conjuntivo que constituía o perimísio apresentava-se ora escasso ora exuberante. Dez (40\%) animais apresentaram tecido adiposo endomisial (Figura 1F). 
Em 55\% das amostras musculares, as lesões inflamatórias apresentavam distribuição focal (leve), em 20\%, multifocal (moderada) e, em 25\%, difusa (acentuada). Os quatro cães em que foram identificados antígenos do parasita por imunohistoqímica apresentavam infiltrado mononuclear, degeneração e necrose de fibras musculares e diminuição do tamanho das fibras musculares. Dois animais (8\%) apresentavam todas as amostras musculares dentro dos padrões histopatológicos de normalidade. A avaliação histopatológica das fibras musculares dos animais do grupo controle encontrou-se dentro dos parâmetros de normalidade, tanto na coloração pela HE, como por TGM. O número absoluto e a percentagem de músculos que apresentavam altera- ções histopatológicas nos animais com leishmaniose visceral e nos cães não infectados encontram-se apresentadas na tabela 1 .

\section{Discussão}

A LVC é uma doença de caráter crônico que pode causar febre, anemia, perda progressiva de peso, linfoadenopatia generalizada, hepato e esplenomegalia, lesões cutâneas, alterações renais, digestórias, cardiorrespiratórias, locomotoras, neurológicas e oculares ${ }^{3,7,20,21,22}$. Quinze cães (60\%) possuíam sintomas de LV e, destes, quatro (8\%) apresentavam caquexia, sugerindo estado avançado da doença. Apesar de Vamvakidis et al. ${ }^{8}$ relatarem a presença de atrofia muscular em $67 \%$ dos animais, no presente estudo evidenciou-se

Tabela 1 - Número absoluto e percentagem (\%) de músculos com alterações de graus leve, moderado e intenso, observadas por meio de exame de 25 cães naturalmente acometidos por leishmaniose visceral (LVC) e de quatro cães não infectados (controle)

\begin{tabular}{|c|c|c|c|}
\hline Parâmetros morfológicos & LVC & Controle & $p$ \\
\hline \multicolumn{4}{|l|}{ degeneração e necrose de miofibras } \\
\hline ausente & 41 & $16(100 \%)$ & \\
\hline leve & 30 & - & $0,0111^{*}$ \\
\hline moderada & 12 & - & \\
\hline intensa & 17 & - & \\
\hline \multicolumn{4}{|l|}{ infiltrado inflamatório } \\
\hline ausente & 76 & $16(100 \%)$ & \\
\hline leve & 11 & - & 0,0959 \\
\hline moderada & 5 & - & \\
\hline intensa & 8 & - & \\
\hline \multicolumn{4}{|l|}{ fibrose } \\
\hline ausente & 74 & $16(100 \%)$ & \\
\hline leve & 20 & - & 0,0594 \\
\hline moderada & 5 & - & \\
\hline intensa & 1 & - & \\
\hline \multicolumn{4}{|l|}{ variação no tamanho das miofibras } \\
\hline ausente & 78 & $16(100 \%)$ & \\
\hline leve & 11 & - & $0,0466^{*}$ \\
\hline moderada & 5 & - & \\
\hline intensa & 6 & - & \\
\hline \multicolumn{4}{|l|}{ presença de tecido adiposo no endomísio } \\
\hline ausente & 85 & $16(100 \%)$ & \\
\hline leve & 8 & - & 0,1442 \\
\hline moderada & 3 & - & \\
\hline intensa & 4 & - & \\
\hline
\end{tabular}

Legenda: $P$ - nível descritivo do teste Mann-Whitney a 5\% de significância; estatística calculada a partir da soma dos escores dos quatro músculos de cada animal 
atrofia muscular moderada a intensa, principalmente dos membros pélvicos, em $20 \%$.

A atividade elétrica insersional alterada, observada em $68 \%$ dos cães que apresentaram resposta diminuída em pelo menos um dos músculos, sugere a ocorrência de atrofia muscular, necrose tecidual ou substituição do tecido muscular por tecido conjuntivo fibroso ou fibroadiposo, o que pode caracterizar quadro de miopatia degenerativa. Por outro lado, em processos inflamatórios ou degenerativos pode-se verificar atividade elétrica insersional aumentada, fato que foi identificado em $24 \%$ dos cães do presente estudo ${ }^{23}$.

Em quadros de miopatias frequentemente notam-se potenciais espontâneos durante a atividade elétrica de repouso, fato que foi observado em $52 \%$ dos animais, sugerindo hiperexcitabilidade de membranas das células musculares ${ }^{23}$. A frequente observação de atividade elétrica insersional diminuída, em $44 \%$ dos músculos, e a moderada frequência de potenciais espontâneos, em $21 \%$ dos músculos, diferem dos resultados eletromiográficos encontrados por Vamvakidis et al. ${ }^{8}$, que verificaram atividade elétrica insersional aumentada com presença de potenciais espontâneos em 70,83\% dos cães com LV. Como as alterações eletrofisiológicas encontradas nas miopatias sofrem variações de acordo com o tipo e a fase evolutiva da enfermidade, nem sempre existe padrão de resposta, principalmente nas polimiosites ${ }^{24}$.

Em miopatias crônicas onde o tecido muscular passa a ser substituído por tecido fibroso ocorre alteração na atividade elétrica voluntária, o que foi observado em $72 \%$ dos cães, confirmando o comprometimento do tecido muscular em casos de LV, mesmo na ausência de evidências clínicas de lesão muscular. Em 16\% dos cães havia amostras musculares cuja única alteração eletromiográfica encontrada foi o recrutamento alterado, sugerindo fase inativa da polimiosite, na qual não se detectam sinais de hiperexcitabilidade das membranas ${ }^{24}$. Essa variedade de resultados é comumente observada em indivíduos com polimiosite ${ }^{23,24}$.
A identificação de antígenos do parasita na musculatura de $26,7 \%$ dos cães com quadro clínico de LV diferiu de resultados de estudos prévios, onde o mesmo foi identificado nos músculos de $66,6 \%{ }^{8}$ e em $86,7 \%{ }^{11}$ dos cães com a doença. Comparando-se os resultados da avaliação histopatológica e da pesquisa de Leishmania sp. no músculo bíceps femoral, realizados por Paciello et al. ${ }^{11}$, é possível verificar uma correlação positiva entre o grau de necrose de miofibras e a quantidade de formas amastigotas identificadas na musculatura. A intensidade da necrose de miofibras e a evidente atrofia muscular, identificada em todos os cães dos estudos anteriores, podem estar relacionadas à identificação de uma maior percentagem de músculos com parasitas em relação aos resultados do presente estudo.

Em $80 \%$ dos cães foram evidenciados vários graus de degeneração e necrose das miofibras, confirmando os achados de Vamvakidis et al. ${ }^{8}$ e Paciello et al. ${ }^{11}$. Entretanto, enquanto Paciello et al. ${ }^{11}$ verificaram necrose moderada a severa em $80 \%$ dos músculos avaliados, no presente estudo, os valores foram da ordem de $29 \%$. Uma possível explicação para essa divergência de resultados pode residir no fato dos autores terem avaliado somente animais com atrofia muscular evidente, o que foi verificado em apenas $20 \%$ dos cães do presente estudo. A ocorrência de fibras em regeneração foi também relatada por Torres e Noronha ${ }^{25}$. Em $48 \%$ dos cães evidenciou-se resposta inflamatória mononuclear peri e endomisial semelhante ao observado em miopatias inflamatórias generalizadas caninas ${ }^{26}$. Esses valores foram inferiores aos verificados por Vamvakidis et al. ${ }^{8}$, os quais, estudando quadros de miosite em cães com LV, identificaram infiltrado inflamatório na musculatura de $92 \%$ dos animais.

A presença de resposta inflamatória mononuclear e da ausência do parasita no tecido muscular da maioria dos cães sugere que a polimiosite possa ser de origem multifatorial. Estudos prévios indicaram a participação de processos imunomediados ${ }^{8}$ e catabólicos ${ }^{27}$ nas lesões musculares de cães com LV. Em modelos experi- 
mentais comprovou-se que o fator de necrose tumoral (TNF) causa proteólise e inibição da lipase lipoproteica no tecido muscular, levando à redução no diâmetro da miofibra, além de alterar a função metabólica da célula, podendo induzi-la à apoptose ${ }^{27}$. Outras interleucinas, como a IL-1 e IL-6 também participam do processo catabólico observado em doenças crônicas como a LV e podem contribuir para a atrofia observada ${ }^{28}$.

A diminuição do tamanho das fibras musculares com distribuição perifascicular, como observada nos animais do presente estudo, é comum em casos de polimiosite em seres humanos ${ }^{25}$. A presença de fibrose peri ou endomisial e presença de tecido adiposo endomisial, que geralmente acompanha a substituição dos miócitos por tecido fibroso, sugerem que nesses casos a miopatia apresentava evolução crônica ${ }^{29}$. Em $8 \%$ dos cães não havia alterações histopatológicas nos músculos avaliados e em $20 \%$ as alterações encontradas não permitiram que se estabelecesse diagnóstico de polimiosite.

Confrontando-se os resultados da eletromiografia e da avaliação histopatológica, verificou-se que todos os cães que possuíam alterações eletromiográficas sugestivas de polimiosite aguda ou crônica tiveram essa fase da enfermidade confirmada por meio do exame histopatológico. Em 8\% dos animais, o exame eletromiográfico encontrava-se dentro dos padrões de normalidade, mas existiam alterações histopatológicas musculares significativas, demonstrando que, embora a eletromiografia seja útil como exame complementar no diagnóstico de miopatias, muitas vezes, apenas a biopsia muscular pode identificar fases iniciais dessas doenças ${ }^{24,25,30,31}$.

Quanto aos cães (12\%) cujas alterações eletromiográficas e histopatológicas não confirmaram quadro de miosite, cabe lembrar que em casos de lesões focais uma amostra de tecido pode não ser representativa do quadro histopatológico global, já que a maioria das lesões em fibras musculares é segmentar ${ }^{8,25,30,32,33}$. A pre- sença de alterações eletromiográficas e histopatológicas na musculatura esquelética de cães com LV, sugestivas de polimiosite, mesmo na ausência de sinais clínicos evidentes da doença, sugere que as alterações musculares observadas nessa doença não são decorrentes exclusivamente do catabolismo proteico que acompanha a enfermidade, como sugerido por vários autores ${ }^{8}$. Em miosites de origem infecciosa normalmente atribui-se o desenvolvimento de lesões a uma ação direta do parasita ou de suas toxinas ${ }^{8}$. Por outro lado, naquelas de origem imunomediada, a etiopatogenia está relacionada à presença de anticorpos circulantes contra miofibras e deposição de imunecomplexos na musculatura. A presença de parasitas na musculatura de apenas $16 \%$ dos cães do presente estudo sugere a participação de uma resposta imune no desenvolvimento das lesões musculares, conforme observado por Vamvakidis et al. ${ }^{8}$. Tal assertiva é reforçada pela observação de que $80 \%$ dos animais avaliados, mesmo com ausência de sintomas evidentes e de parasitas na musculatura, possuíam alterações no exame eletromiográfico compatíveis com quadros de miopatia.

Como não foi investigada a participação de resposta imune celular e humoral na miopatia dos cães da presente pesquisa, novos estudos devem ser realizados para elucidar a etiopatogenia das lesões musculares na LVC.

\section{Conclusões}

As alterações observadas no presente estudo permitiram concluir que mesmo na ausência de sinais clínicos de comprometimento muscular, a maior parte dos cães infectados por L. infantum apresenta polimiosite crônica. 


\section{Referências}

1. WOLSCHRIJN, C. F.; MEYER, H. P.; HAZEWINKEL, H. A. W.; WOLVEKAMP, W. T. C. Destructive polyarthritis in a dog with leishmaniasis. Journal of Small Animal Practice, v. 37, n. 12, p. 601-603, 1996.

2. BURACCO, P.; ABATE, O.; GUGLIELMINO, R.; MORELLO, E. Osteomyelitis and arthrosynovitis associated with leishmania donovani infection in a dog. Journal of Small Animal Practice, v. 38, n. 1, p. 29-30, 1997.

3. FEITOSA, M. M.; IKEDA, F. A.; LUVIZOTTO, M. C. R.; PERRI, S. H. V. Aspectos clínicos de cães com leishmaniose visceral no município de Araçatuba - São Paulo (Brasil). Clínica Veterinária, v. 5, n. 28, p. 36-44, 2000.

4. MCCONKEY, S. E.; LÓPEZ, A.; SHAW, D.; CALDER, J. Leishmanial polyarthritis in a dog. Canadian Veterinary Journal, v. 43, p. 607, 2002.

5. AGUT, A.; CORZO, N.; MURCIANO, J.; LAREDO, F. G.; SOLER, M. Clinical and radiographic study of bone and joint lesions in 26 dogs whit leishmaniasis. Veterinary Record, v. 153 , p. 648-652, 2003.

6. BANETH, G. Leishmaniasis. In: GREENE, C. E. Infectious diseases of the dog and cat. 3. ed. Philadelphia: Elsevier, 2006. p. 685-698.

7. SILVA, A. R. S.; ROSSI, C. N.; GOMES, A. A. D.; VIEIRA, R. F. C.; IKEDA-GARCIA, F. A.; CIARLINI, P. C.; CIARLINI, L. D. R. P.; MARCONDES, M. Osteoartrite por Leishmania sp. em um cão Pit Bull - relato de caso. In: XXVIII Congresso Brasileiro da ANCLIVEPA, 2007, Florianópolis. Acta Scientiae Veterinariae, 2007, v. 35, p. 545-546, 2007.

8. VAMVAKIDIS, C. D.; KOUTINAS, A. F; KANAKOUDIS, G.; GEORGIADIS, G.; SARIDOMICHELAKIS, M. Masticatory and skeletal muscle myositis in canine leishmaniasis (Leishmania infantum). Veterinary Record, v. 146, n. 24, p. 698-703, 2000

9. MACRI, B.; GUARDA, F. A case of dermatomyositis due to leishmaniasis in a dog. Schweizer Archiv fur Tierheilkunde, v. 129, n. 5 , p. 265-270, 1987

10.EUGÊNIO, F. R.; SILVA, A. M.; ANDRADE, A. L.; MAIA, C. A. A.; BEVILACQUA, L.; ZANETTE, M. F.; CARVALHO, F. P.; LUVIZOTTO, M. C. Miosite por Leishmania sp de músculos mastigatórios - relato de caso. In: CONGRESSO PAULISTA DE CLINICOS VETERINÁRIOS DE PEQUENOS ANIMAIS - CONPAVEPA, 2., 2002, São Paulo. Anais... São Paulo: Escritório Editorial, 2002. p. 109-110.

11.PACIELLO, O.; OLIVA, G.; GRADONI, L.; MANNA, L.; MANZILLO, V. F.; WOJCIK, S.; TRAPANI, F.; PAPPARELLA, S. Canine inflammatory myophaty associated with Leishmania infantum infection. Neuromuscular Disorders, v. 19, n. 2, p. 124-130, 2009.

12.NARANJO, C.; FONDEVILLA, D.; LEIVA, M.; ROURA, X.; PEÑA, T. Detection of Leishmania spp. and associated inflammation in ocular-associated smooth and striated muscles in dogs with patent leishmaniosis. Veterinary Ophthalmology, v. 13, n. 3, p. 139-143, 2010.

13. ALVES, G. B.; PINHO, F. A.; SILVA, S. M.; CRUZ, M. S.; COSTA, F. A. Cardiac and pulmonary alterations in symptomatic and asymptomatic dogs infected naturally with Leishmania (Leishmania) chagasi. Brazilian Journal of Medical and Biological Research, v. 43, n. 3, p. 310-315, 2010.

14.LÓPEZ-PEÑA, M.; ALEMAÑ, N.; MUNÕZ, F.; FONDEVILA, D.; SUÁREZ, M. L.; GOICOA, A.; NIETO, J. M. Visceral leishmaniasis with cardiac involvement in a dog: a case report. Acta Veterinaria Scandinavica, v. 51, n. 1, p. 20-22, 2009.
15.RIBEIRO, V. M.; SILVA, B. C.; VIEIRA, F. G.; FIGUEIREDO, M. M.; TAFURI, W.; VALLE G. R.; PEDERSOLI, V.; RACHID M. A. Heart lesions associated with visceral leishmaniasis of naturally infected dogs. In: WORLD CONGRESS ON LEISHMANIOSIS, 4., 2009, Lucknow. Abstract Book... Lucknow: WorldLeish4, 2009. p. 275-276.

16.PINTO, A. J.; FIGUEIREDO, M. M.; SILVA, F. L.; MARTINS, T.; MICHALICK, M. S.; TAFURI, W. L.; TAFURI, W. L. Histopathological and parasitological study of the gastrointestinal tract of dogs naturally infected with Leishmania infantum. Acta Veterinaria Scandinavica, v. 53, n. 1, p. 67-74, 2011.

17.LIMA, V. M. F.; BIAZZONO, L.; SILVA, A. C.; CORREA, A. P. F. L.; LUVIZOTTO, M. C. R. Serological diagnosis of visceral leishmaniasis by an enzyme immunoassay using protein $\mathrm{A}$ in naturally infected dogs. Pesquisa Veterinária Brasileira, v. 25, n. 4 , p. 215-218, 2005 .

18.NUNES, C. M.; DIAS, A. K.; GOTTARDI, F. P.; DE PAULA, H. B.; AZEVEDO, M. A.; DE LIMA, V. M.; GARCIA, J. F. Polymerase chain reaction evaluation for canine visceral leishmaniasis diagnosis in dog blood samples. Brazilian Journal Veterinary Parasitology, v. 16, n. 1, p. 5-9, 2007.

19.THOMSON, F. K.; BOWEN, J. M. Electrodiagnostic testing: mapping and clinical use of motor points in the dog. Journal of the American Veterinary Medical Association, v. 159, n. 12 , p. 1763-1770, 1971

20.CIARAMELLA, P.; OLIVA, G.; LUNA, R. D.; GRADONI, L.; AMBROSIO, R.; CORTESE, L.; SCALONE, A.; PERSECHINO, A. A restropective clinical study of canine leishmaniasis in 150 dogs naturally infected by Leishmania infantum. Veterinary Record, v. 141, n. 21, p. 539-543, 1997.

21.KOUTINAS, A. F.; POLIZOPOULOU, Z. S.; SARIDOMICHELAKIS, $\quad M$. N.; ARGYRIADIS, D.; FYTIANOU, A.; PLEVRAKI, K. G. Clinical considerations on canine visceral leishmaniasis in Greece: a retrospective study of 158 cases (1989-1996). Journal of the American Animal Hospital Association, v. 35, n. 5, p. 376-383, 1999.

22.BANETH, G.; KOUTINAS, A. F.; SOLANO-GALLEGO, L.; BOURDEAU, P.; FERRER, L. Canine leishmaniosis - new concepts and insights on an expanding zoonosis: part one. Trends in Parasitology, v. 24, n. 7, p. 324-330, 2008.

23. PINTO, L. C. Neurofisiologia clínica: princípios básicos e aplicações. São Paulo: Atheneu, 2006. p. 109-119, 219-233.

24.DUMITRU, D.; ZWARTS, M. J.; AMATO, A. A. Electrodiagnostic medicine. 2. ed. Philadelphia: Hanley \& Belfus, 2002. $1524 \mathrm{p}$.

25.TORRES, L. F. B.; NORONHA, L. Músculos esqueléticos. In: BRASILEIRO-FILHO, G. Bogliolo patologia. 7. ed. Rio de Janeiro: Guanabara Koogan, 2006. p. 1036-1061.

26.PUMAROLA, M.; MOORE, P. F.; SHELTON, G. D. Canine inflammatory myopathy: analysis of cellular infiltrates. Muscle \& Nerve, v. 29, n. 6, p. 782-789, 2004.

27.PEARSON, R. D.; COX, G.; JERONIMO, S. M.; CASTRACANE, J.; DREW, J. S.; EVANS, T.; DE ALENCAR, J. E. Visceral leishmaniasis: a model for infection-induced cachexia. American Journal of Tropical Medicine and Hygiene, v. 47, n. 1/2, p. 8-15, 1992.

28.HARRISON, L. H.; NAIDU, T. G.; DREW, J. S.; DE ALENCAR, J. E.; PEARSON, R. D. Reciprocal relationships between undernutrition and the parasitic disease visceral leishmaniasis. Reviews Infectious Diseases, v. 8, n. 3, p. 447-453, 1986.

29.DUBOWITZ, V.; SEWRY, A. C. Muscle biopsy: a pratical approach. 3. ed. Saunders: Elsevier, 2007.611 p. 
30. KORNEGAY, J. N. Distúrbios dos músculos esqueléticos. In: ETTINGER, S. J.; FELDMMAN, E. C. Tratado de medicina interna veterinária: moléstias do cão e do gato. 4. ed. São Paulo: Manole. 1997. p. 1026-1038.

31. MCGAVIN, M. D. Músculos. In: CARLTON, W. W. MCGAVIN, M. D. Patologia veterinária especial de Thomson. 2. ed. Porto Alegre: Artmed, 1998. p. 417-447.
32.PODELL, M. Inflammatory myopathies. The Veterinary Clinics of North América (Small Animal Practice), v. 32, n. 1, p. 147-167, 2002.

33. VALENTINE, B. A.; MCGAVIN, M. D. Skeletal muscle. In: MCGAVIN, M. D.; ZACHARY, J. F. Pathologic basis of veterinary disease. 4 . ed. St. Louis: Mosby Elsevier, 2007. p. 973-1039. 